\title{
170. An Investigation of Bone-Marrow in Palaeanthropic Man in Israel
}

\author{
By Seizo Katsunuma, M.J.A., Hisashi Suzuki, ${ }^{*}$ \\ and Kanji FurUta**)
}

(Comm. Dec. 12, 1962)

The present authors reported previously in 1960 in this proceedings (Vol. 36, No. 7) about the presence of hemoagglutinogen AB and the positive peroxidase reaction in eosinophilic leucocytes as to the bone-marrow of the Upper and Middle Pleistocene man in Japan.

One of them, anthropologist, Professor H. Suzuki et al, Department of Anthropology, University of Tokyo excavated a human skeleton at Amud Cave, Wadi Amud, Upper Galilee, Israel, July 14, 1961. It was determind anthropologically by H. Suzuki and geologically by Professor F. Takai, Department of Geology, University of Tokyo, that the skeleton belonged to the Palaeanthropic form of fossil man.

Bone-marrow specimens were taken from the skull of the skeleton for the purpose of some investigations and the following results were obtained:

1) The blood agglutinogen $\mathrm{AB}$ was clearly proved by the absorption method.

2) Peroxidase reaction was also proved in groups like leucocytes found in the material.

Anthropological full details of the skeleton will be reported by H. Suzuki who undertook the expedition for the said excavation as the leader of the group.

*) Department of Anthropology, University of Tokyo.

**) Legal Medicine, University of Nagoya. 